\title{
Lightning Changes in Response to Global Warming in Rio de Janeiro, Brazil
}

\author{
Osmar Pinto Jr., Iara R. C. A. Pinto \\ Brazilian Institute of Space Research (INPE), S. J. dos Campos, Brazil \\ Email: osmar.pinto@inpe.br, iara.pinto@inpe.br
}

How to cite this paper: Pinto Jr., O., \& Pinto, I. R. C. A. (2020). Lightning Changes in Response to Global Warming in Rio de Janeiro, Brazil. American Journal of Climate Change, 9, 266-273.

https://doi.org/10.4236/ajcc.2020.93017

Received: July 7, 2020

Accepted: September 5, 2020

Published: September 8, 2020

Copyright (อ 2020 by author(s) and Scientific Research Publishing Inc. This work is licensed under the Creative Commons Attribution International License (CC BY 4.0).

http://creativecommons.org/licenses/by/4.0/

(c) (i) Open Access

\begin{abstract}
Physical concepts based on the Clausius-Clapeyron relation and on the thermodynamics and aerosol characteristics associated with updrafts, global climate models assuming different parametrizations and lightning-related output variables, and lightning-related data (thunderstorm days) are being used to infer the lightning incidence in a warmer planet, motivated by the global warming observed. In all cases, there are many gaps to be overcome making the lightning response to the global temperature increase still unpredicted. Values from almost $0 \%$ (no increase) to $100 \%$ have been estimated, being $10 \%$ the most common value. While the physical concepts address only part of the problem and the global climate models need to make many simple assumptions, lightning-relate data have strong time and space limitations. In this context, any new evidence should be considered as an important contribution to better understand how will be the lightning incidence in the future. In this article, we described new results about the occurrence of thunderstorms from 1850 to 2010 (a period of 160 years) in the city of Rio de Janeiro, in the Southeast of Brazil. During this period thunderstorm days were recorded in the same location, making this time series one of the longest series of this type available worldwide. The data support an increase of $21 \%$ in the mean annual thunderstorm days during the period, while surface temperature increased by $0.6^{\circ} \mathrm{C}$ during the period. Considering that the mean annual number of thunderstorm in the beginning of this period was 29 , we found an increase of one thunderstorm day per $0.1^{\circ} \mathrm{C}$ of increase in the surface temperature. Assuming that the number of lightning flashes per thunderstorm remains approximately constant during the period, this number corresponds to an increase in the lightning flash rate of approximately $35 \%$ per ${ }^{\circ} \mathrm{C}$ of increase of temperature. In addition, considering that the increase of the global temperature during the period was almost the same that observed in Rio de Janeiro, we can conclude that this increase in the lightning flash rate is due to the global warming with no effect of urban activity. Finally, we found that
\end{abstract}


monthly thunderstorm days and monthly mean surface temperature show a linear correlation with a coefficient of 0.9 along the period.

\section{Keywords}

Lightning, Global Change, Rio de Janeiro, Brazil

\section{Introduction}

Lightning is a natural hazard with important climatic effects on longer time-scales through $\mathrm{NO}_{\mathrm{x}}$ production and forest fire ignition. In most cases, it is accompanied by strong downdrafts, hail and hazardous precipitation that often entail significant economic losses. It also poses threats to aviation safety, renewable energy production by wind-turbines, and electric power utilities. In this context, its future activity in a warmer climate is of concern to the society (Williams \& Guha, 2019; Herring et al., 2018).

How global lightning may respond to a warmer climate is one of the main open issues in the atmospheric science at present time. From the theoretical point of view, the reason for that gap in our present knowledge is derived from the limits of our current ability to understand in detail the global distribution of lightning in the present climate, in particular the contrast in lightning activity between land and ocean (Williams, 2005; Humphreys, 1964; Williams \& Stanfill, 2002; Williams et al., 1999). One particular challenge is that both temperature (involving changes in CAPE and in the cloud base height) and aerosol (involving changes in the cloud condensation nuclei) play important roles in lightning activity in the present climate (Williams \& Guha, 2019; Houghton, 1985; Stolz, Rutledge, \& Pierce, 2015). From the data point of view, in turn, the reason is derived from our limited amount of data to find patterns in a multi-decadal time scale.

For studies on lightning variability on time scales longer than the typical lifetimes of lightning detection networks (a few decades), researchers have use thunderstorm day data (Pinto Jr., 2015) and model calculations (Price \& Rind, 1992). Thunderstorm day observations have been underway at meteorological stations and airports worldwide for more than a century, but only in a few locations, so that there is a clear lack of reliable, long-duration time-series. Only at high northern latitudes there is a clear tendency for larger increases in the thunderstorm day counts in response to the current global warming (Hansen, Ruedy, Sato, \& Lo, 2010; Williams, 2009).

Global climate models (GCM), in turn, are very sensitive to the physical parameterizations adopted, because their present resolution cannot adequately portray microphysical processes that are conducive to electrical activity such as ice and graupel collisions or ice multiplication. Thus, GCM cannot give accurate depiction of future cloud properties, and give only general trends, so that results have shown large variations including increases (Romps, Seeley, Vollaro, \& Mo- 
linari, 2014) and even decreases (Finney et al., 2018) in the lightning activity in a warmer planet.

The expectations for the future planetary lightning activity have been summarized recently (Williams \& Guha, 2019). In spite of the large body of evidence suggesting that the lightning activity should increase in a warmer planet, large uncertainties remain. If total water vapor in the Earth's atmosphere follows the Clausius-Clapeyron relationship, one expects greater total water and more condensate in a warmer world, and given the need for condensates for lightning, greater lightning is expected. Given the evidence for the role of CAPE in lightning in the present climate, more lightning is expected in a warmer climate if CAPE increases. Early speculation showed CAPE to be a climate invariant (Emanuel, Neelen, \& Bretherton, 1994). More recent global climate models, however, show larger CAPE in warmer climates (Williams \& Guha, 2019). Theoretical calculations in equilibrium atmospheres show CAPE scaling with the Clausius-Clapeyron relationship (Williams \& Guha, 2019). For all of these reasons, one expects greater lightning in a warmer world, although large geographical variations should be expected.

From the global climate model point of view, one recent study (Finney et al., 2018) predicts less tropical lightning in a warmer world. However, the prediction is controversial (Williams \& Guha, 2019).

Further discussion on this issue and predictions for the behavior of lightning in a warmer climate can be found elsewhere (Yair, 2018).

Finally, from the present knowledge, lightning enhancements are expected over a finite range of $\mathrm{CCN}$ concentrations, Above some level, the lightning activity is expected to flatten and then decrease (Mansell \& Ziegler, 2013), making the effect of $\mathrm{CCN}$ concentrations on lightning more difficult to evaluate.

In this article thunderstorm day counts in the city of Rio de Janeiro (Brazil) from 1850 to 2010 are analyzed. Figure 1 shows the entrance of the Guanabara Bay at 1880 (when the first photos were taken) and in 2010. The comparison of the photos shows the city growth at same time that shows the very pronounced mountainous terrain.

Along the above period the long-term record of mean global temperature based on averaging of surface thermometers shows an increase of the order of $0.6^{\circ} \mathrm{C}$. Figure 2 shows the mean global temperature during this period.

\section{Data Analysis}

Data of the thunderstorm occurrence (thunderstorm days counts) from 1850 to 2010 (a period of 160 years) in the city of Rio de Janeiro, in the Southeast of Brazil, were analyzed. During this period thunderstorm days were recorded in the same location, making this time series one of the longest series of this type available worldwide.

Figure 3 shows the monthly total number of thunderstorm days for two 30-years periods, one at the beginning of the time series (1851-1880) and the other at the end of the time series (1981-2010), when we have an increase in the 


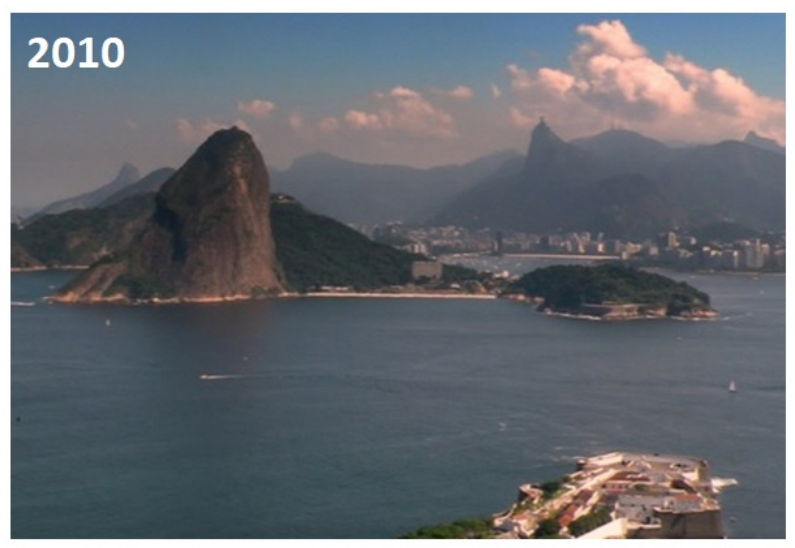

\section{0}

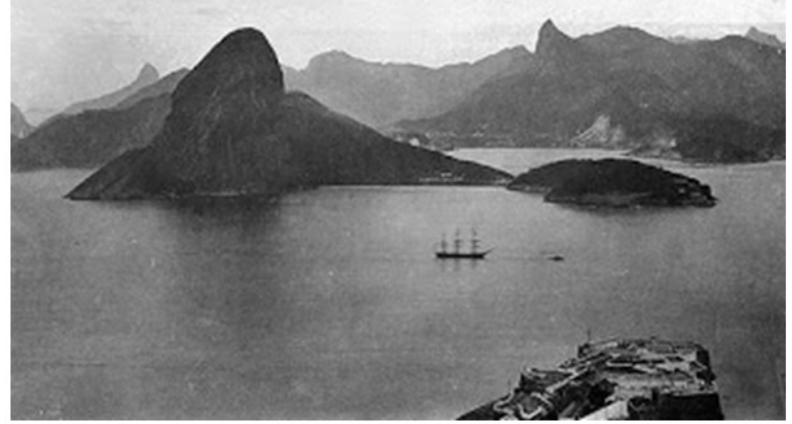

Figure 1. The entrance of the Guanabara Bay in 1880 and 2010.

Temperature anomalies ${ }^{\circ} \mathrm{C}$

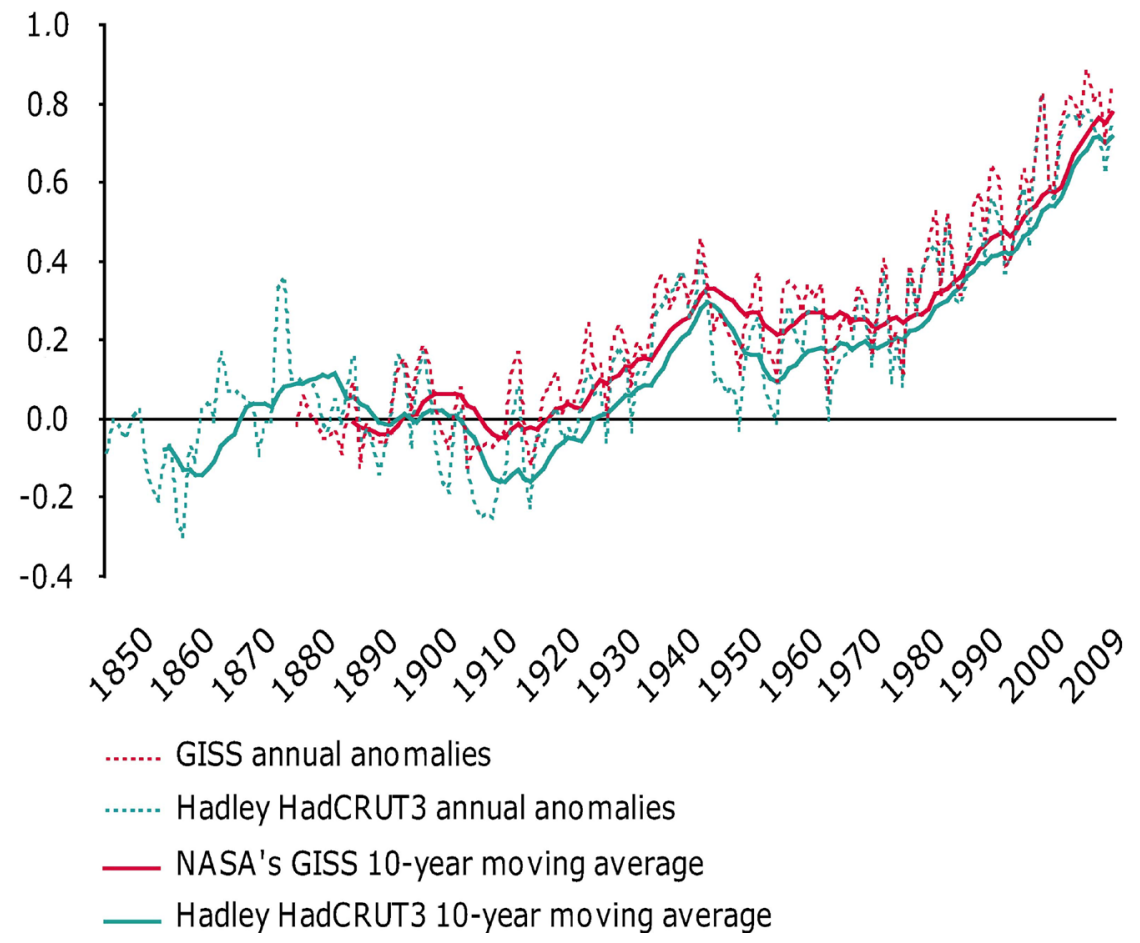

Figure 2. Global temperature anomaly in the period from 1850 to 2010 based on the Hadley Center and NASA. 


\section{TD Rio de Janeiro}

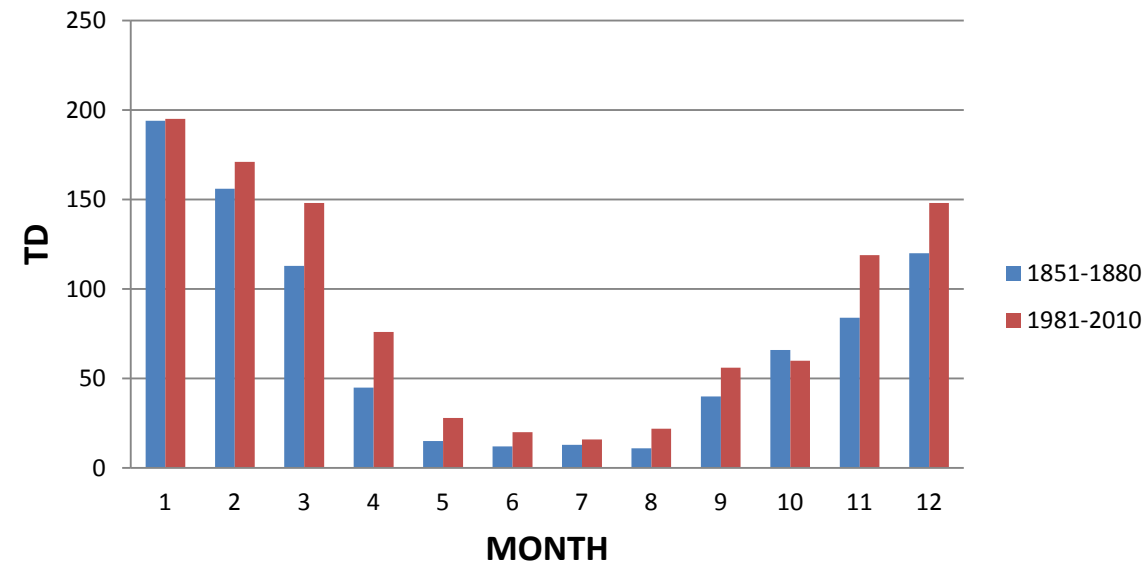

Figure 3. The monthly total number of thunderstorm days (TD) for two 30-years periods, one at the beginning of the time series (1851-1880) and the other at the end of the time series (1981-2010).

global mean temperature. It can be seen in Figure 3 that TD increases in all months during the period.

Figure 4 shows mean monthly surface temperatures in the city of Rio de Janeiro for the same 30-years periods in Figure 3. The same behavior seen in Figure 3 can be seen in Figure 4, that is, the surface temperature increases in all months during the period.

From the analysis of the data shown in Figure 3 and Figure 4 we found an increase of $21 \%$ in the mean annual thunderstorm days during the period, while surface temperature increased by $0.6^{\circ} \mathrm{C}$ during the period. Considering that the mean annual number of thunderstorm in the beginning of this period was 29 , we found an increase of one thunderstorm day per $0.1^{\circ} \mathrm{C}$ of increase in the surface temperature. Assuming that the number of lightning flashes per thunderstorm remains approximately constant during the period this number corresponds to an increase in the lightning flash rate of approximately $35 \%$ per ${ }^{\circ} \mathrm{C}$ of increase of temperature. In addition, considering that the increase of the global temperature during the period was almost the same that observed in Rio de Janeiro we can conclude that this increase in the lightning flash rate is due to the global warming with no effect of urban activity. This conclusion is in agreement with the fact that in the city of Rio de Janeiro the mountain terrain and the ocean are the main features related to the thunderstorm formation.

Finally, Figure 5 shows that monthly thunderstorm days and monthly mean surface temperature are very correlated with a linear correlation coefficient of 0.9 or higher at the two 30-years intervals giving additional support to a casual relation between both.

\section{Conclusion}

The thunderstorm day data analyzed in this article support an increase of $21 \%$ in 


\section{TEMPERATURE Rio de Janeiro}

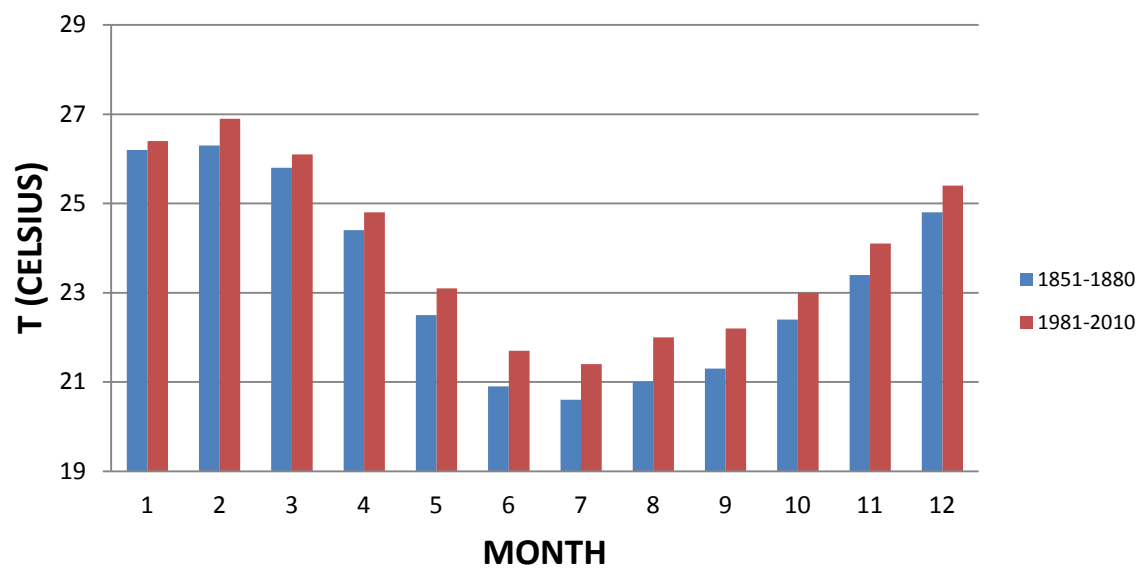

Figure 4. Mean monthly temperatures ( $\mathrm{T}$ ) for two 30-years periods, one at the beginning of the time series (1851-1880) and the other at the end of the time series (1981-2010).

\section{REGRESSION 1851-1880}

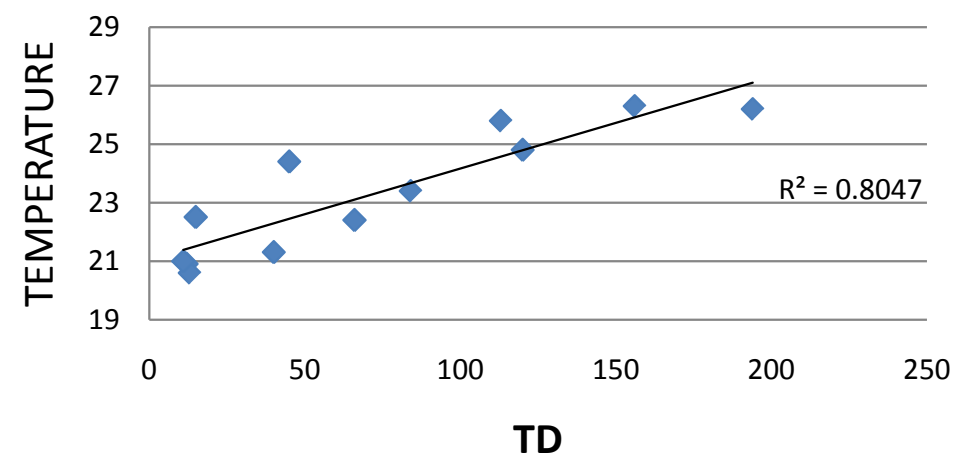

(a)

REGRESSION 1981-2010

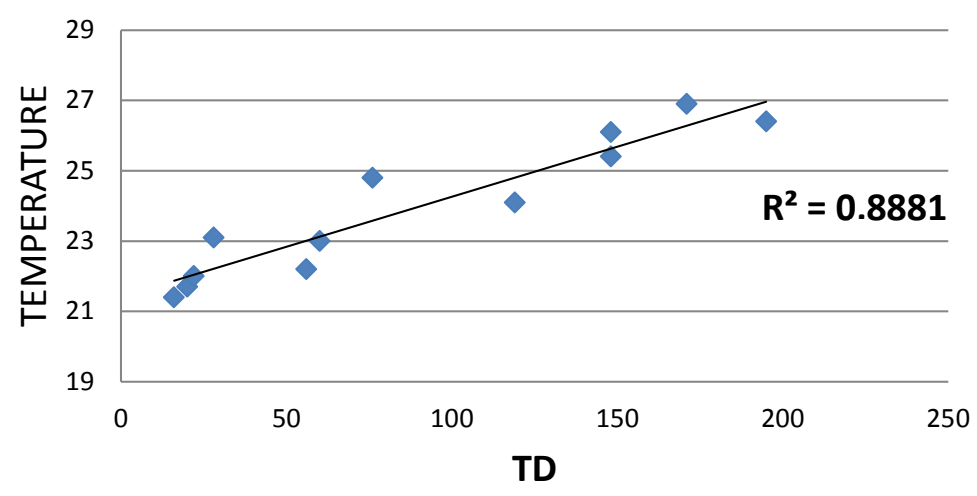

(b)

Figure 5. Scatter plot showing a linear correlation between the mean monthly temperatures and thunderstorm days for two 30-years periods: (a) 1851-1880 and (b) 1981-2010.

the mean annual thunderstorm days during the period, while surface temperature increased by $0.6^{\circ} \mathrm{C}$ during the period. Considering that the mean annual 
number of thunderstorm in the beginning of this period was 29 , we found an increase of one thunderstorm day per $0.1^{\circ} \mathrm{C}$ of increase in the surface temperature. Assuming that the number of lightning flashes per thunderstorm remains approximately constant during the period (a reasonable assumption in the lack of lightning information in the beginning of the period) this number corresponds to an increase in the lightning flash rate of approximately $35 \%$ per ${ }^{\circ} \mathrm{C}$ of increase of temperature. In addition, considering that the increase of the global temperature during the period was almost the same that observed in Rio de Janeiro, we can conclude that this increase in the lightning flash rate is due to the global warming with no effect of urban activity, a result that is in agreement with the fact that in the city of Rio de Janeiro the mountain terrain and the ocean are the main features related to the thunderstorm formation.

\section{Conflicts of Interest}

The authors declare no conflicts of interest regarding the publication of this paper.

\section{References}

Emanuel, K. A., Neelen, J. D., \& Bretherton, C. S. (1994). On Large-Scale Circulations on Convecting Atmospheres. Quarterly Journal of the Royal Meteorological Society, 120, 1111-1143. https://doi.org/10.1002/qj.49712051902

Finney, D. L., Doherty, R. M., Wilde, O., Stevenson, D. S., MacKenzie, I. A., \& Blyth, A. M. (2018). A Projected Decrease in Lightning under Climate Change. Nature Climate Change, 8, 210-213. https://doi.org/10.1038/s41558-018-0072-6

Hansen, J., Ruedy, R., Sato, M., \& Lo, K. (2010). Global Surface Temperature Change. Reviews of Geophysics, 48, RG4004. https://doi.org/10.1029/2010RG000345

Herring, S. C., Christidis, N., Hoell, A., Kossin, J. P., Schreck III, C. J., \& Scott, P. A. (2018). Explaining Extreme Event of 2016 from a Climate Perspective. Bulletin of the American Meteorological Society, 99, S1-S157. https://doi.org/10.1175/BAMS-ExplainingExtremeEvents2016.1

Houghton, H. G. (1985). Physical Meteorology. Cambridge, MA: MIT Press.

Humphreys, W. J. (1964). The Physics of the Air. New York: Dover Publications.

Mansell, E. R., \& Ziegler, C. L. (2013). Aerosol Effects on Simulated Storm Electrification and Precipitation in a Two-Moment Bulk Microphysics Model. Journal of the Atmospheric Sciences, 70, 2032-2050. https://doi.org/10.1175/JAS-D-12-0264.1

Pinto Jr., O. (2015). Thunderstorm Climatology of Brazil: ENSO and Tropical Atlantic Connections. International Journal of Climatology, 35, 871-878. https://doi.org/10.1002/joc.4022

Price, C., \& Rind, D. (1992). A Simple Lightning Parameterization for Calculating Global Lightning Distributions. Journal of Geophysical Research, 97, 9919-9933. https://doi.org/10.1029/92JD00719

Romps, D. M., Seeley, J. T., Vollaro, D., \& Molinari, J. (2014). Projected Increase in Lightning Strikes in the United States Due to Global Warming. Science, 346, 851-854. https://doi.org/10.1126/science. 1259100

Stolz, D. C., Rutledge, S. R., \& Pierce, J. R. (2015). Simultaneous Influences of Thermodynamics and Aerosols on Deep Convection and Lightning in the Tropics. Journal of 
Geophysical Research: Atmospheres, 120, 6207-6231.

https://doi.org/10.1002/2014JD023033

Williams, E. R. (2005). Lightning and Climate: A Review. Atmospheric Research, 76, 272-287. https://doi.org/10.1016/j.atmosres.2004.11.014

Williams, E. R. (2009). The Global Electrical Circuit: A Review. Atmospheric Research, 91, 140-152. https://doi.org/10.1016/j.atmosres.2008.05.018

Williams, E., \& Guha, A. (2019). Lightning and Climate Change. In Proceedings of the International Seminar on Lightning Protection. São Paulo: Institute of Energy and Environment of the University of São Paulo.

Williams, E., \& Stanfill, S. (2002). The Physical Origin of the Land-Ocean Contrast in Lightning Activity. Comptes Rendus-Physique, 3, 1277-1292.

https://doi.org/10.1016/S1631-0705(02)01407-X

Williams, E., Rosenfeld, D., Madden, N., Labrada, C., Gerlach, J., \& Atkinson, L. (1999). The Role of Boundary Layer Aerosol in the Vertical Development of Precipitation and Electrification: Another Look at the Contrast between Lightning over Land and over Ocean. In Proceedings of the 11th International Conference on Atmospheric Electricity. Guntersville: International Commission on Atmospheric Electricity.

Yair, Y. (2018). Lightning Hazards to Human Societies in a Changing Climate. Environmental Research Letters, 13, Article ID: 123002.

https://doi.org/10.1088/1748-9326/aaea86 